\title{
A EXPERIÊNCIA DE ROSA VERMELHA NO CONTEXTO DO ALCOOLISMO PATERNO
}

Antonio Richard Carias

Pontifícia Universidade Católica de Campinas

Tânia Mara Marques Granato

Pontifícia Universidade Católica de Campinas
Recebido em: 12/12/2019

$1^{\text {a }}$ revisão em: 14/06/2020

Aceito em: 26/09/2020

\section{RESUMO}

Os filhos de alcoolistas sofrem o impacto de uma relação parental marcada pela violência e imprevisibilidade. O objetivo deste estudo é ilustrar a experiência emocional de filhos de alcoolistas com o relato emblemático de um dos 12 participantes de uma pesquisa psicanalítica empírica. Foi realizada uma entrevista psicanalítica com Rosa Vermelha por meio do uso de uma Narrativa Interativa sobre o drama de um filho que aguarda a chegada do pai alcoolizado. Rosa completou a narrativa expressando-se imaginativamente sobre a convivência com o progenitor. O material narrativo foi analisado à luz da psicanálise winnicottiana, resultando em quatro campos de sentidos que comunicam a experiência emocional de filhos de alcoolistas: "Marcas da Violência"; "Desejo Soberano", "Sobrevivendo ao Caos" e "De volta à minha vida". O intenso sofrimento emocional desses filhos que precisam assumir responsabilidades precocemente enseja a produção de futuras pesquisas que subsidiem práticas no contexto do alcoolismo.

Palavras-chave: abuso de álcool; violência na família; psicanálise. 


\title{
RED ROSE'S EXPERIENCE IN THE CONTEXT OF HER FATHER'S ALCOHOLISM
}

\author{
ABSTRACT
}

Children of alcoholics suffer the impact of a parental relationship characterized by violence and unpredictability. The objective of this study is to illustrate the emotional experience of children of alcoholics by the emblematic account of one of the 12 participants of an empirical psychoanalytic study. A psychoanalytic interview was conducted with the participant Red Rose by means of an Interactive Narrative about the suffering of a child awaiting the arrival of the intoxicated father. Rose completed the narrative through imaginative ideas about living with the alcoholic parent. The narrative material was analyzed in the light of winnicottian psychoanalysis, resulting in four fields of affective-emotional meaning which convey the emotional experience of children of alcoholics: "Scars of Violence"; "Sovereign Desire", "Surviving to Chaos" and "Back to my Life". The intense emotional suffering of those children who have early to take responsibilities suggests the need for further studies to subsidize practices in the context of alcoholism.

Keywords: alcohol abuse; family violence; psychoanalysis.

\section{LA EXPERIENCIA DE ROSA ROJA EN EL CONTEXTO DEL ALCOHOLISMO PATERNO}

\section{RESUMEN}

Los hijos de alcohólicos sufren el impacto de una relación parental marcada por la violencia e imprevisibilidad. El objetivo de este estudio es presentar la experiencia emocional de hijos de alcohólicos con el relato emblemático de uno de los 12 participantes de una investigación psicoanalítica empírica. Se realizó una entrevista con la participante Rosa Roja utilizando una Narrativa Interactiva (NI) sobre el drama de un hijo que espera la llegada del padre alcoholizado. Rosa la completó expresándose imaginativamente sobre la convivencia con el progenitor alcohólico. El material narrativo fue analizado a la luz del psicoanálisis winnicottiana, resultando en cuatro campos de sentidos afectivo-emocionales: "Marcas de la Violencia"; "Deseo Soberano", "Sobreviviendo al Caos" y "De vuelta a casa". El intenso sufrimiento emocional de quienes necesitan madurar y asumir responsabilidades precozmente da lugar a la producción de nuevas investigaciones que subsidien prácticas psicosociales en el contexto del alcoholismo.

Palabras clave: abuso de alcohol; violencia doméstica; psicoanálisis. 


\section{INTRODUÇÃO}

O presente estudo se baseia na história de Rosa Vermelha, uma entre 12 participantes de uma pesquisa empírica psicanalítica sobre a experiência emocional de filhos adultos de pessoas dependentes de álcool. A escolha pela narrativa de Rosa se deu por seu caráter emblemático, na medida em que sua história sintetiza elementos dramáticos relatados pelos demais participantes. Deste modo, tomamos o relato de Rosa Vermelha como produção de um coletivo: filhos adultos que viveram o drama do alcoolismo paterno na infância e adolescência na companhia do progenitor.

Rosa cresceu em uma família marcada pelo alcoolismo paterno, o que nos motiva a apresentar os impactos desta convivência familiar. De acordo com Haverfiel, Theiss e Leustek (2015) e Mangueira e Lopes (2014), a família do alcoolista apresenta dificuldades na comunicação entre seus membros e na divisão de tarefas, visto que a pessoa dependente de álcool costuma apresentar condutas impulsivas e imprevisíveis que desestabilizam o ambiente familiar. Segundo os autores, neste contexto ambiental prevalecem a falta de confiança, alto nível de conflito, comunicação hostil, dificuldades na resolução de problemas, prejuízos nas interações familiares e até mesmo o adoecimento mental dos envolvidos. Entretanto, Teixeira, Hoepers, Correa, Dagostin e Soratto (2015) e Lopes, Marcon e Decesaro (2015) observam que a família mantém viva a esperança de que o alcoolista pare de beber, apesar do desgaste emocional que essa convivência marcada pela violência doméstica e por dificuldades financeiras implica.

Além de compartilharem as angústias vividas pelos demais familiares, os filhos de alcoolistas vivenciam angústias próprias de sua condição. Hagström e Forinder (2019) realizaram um estudo longitudinal para compreender a experiência emocional de filhos de alcoolistas. Ao entrevistarem os mesmos participantes durante a infância, adolescência e vida adulta, os autores identificaram características em comum na experiência deste coletivo. A exposição frequente à violência doméstica e/ou negligência de cuidados resultou no sentimento de abandono e de vulnerabilidade, segundo a experiência dos participantes de Hagström e Forinder (2019). A dupla face do progenitor dependente de álcool que ora está sóbrio, ora alcoolizado gera angústia nos filhos, que se sentem impotentes diante desta imprevisível dualidade. Somada a essa angústia, outras características desse sofrimento foram identificadas, como a necessidade de os filhos criarem estratégias ao longo da vida para conter o consumo de álcool de seu progenitor. Apesar da resiliência sugerida por tais condutas de cuidado, destaca-se o sentimento de solidão referido pelos participantes durante a infância e a adolescência.

Tinnfält, Fröding, Larddon e Dalal (2018) também identificaram sentimentos de tristeza nos filhos frente ao consumo de álcool dos pais. Na tentativa de controlar a situação, os participantes escondem dinheiro e/ou bebidas alcoólicas do progenitor e vivem a experiência de se ausentar psiquicamente do vivido para 
suportá-lo. Woodside (1988) reconhece o sofrimento dos filhos de alcoolistas como um problema grave de saúde pública que deve ser trabalhado em âmbito político-assistencial. Segundo a autora, a imprevisibilidade do ambiente familiar alcoolista tende a produzir sentimentos de insegurança, ansiedade, medo e culpa nos filhos. Furtado et al. (2002) e Pereira, Pimentel, Espínola, Azevedo e Filha (2015) reconhecem que o ambiente instável do lar alcoolista pode favorecer o surgimento de transtornos psiquiátricos nos filhos ao longo da infância e adolescência.

A relação do pai e/ou mãe alcoolista com os seus filhos pode se manifestar de forma violenta e/ou negligente como aponta o estudo de Santos, Silva e Silva (2015) cuja participante relata que, desde a infância, teve que mobilizar recursos emocionais e financeiros para cuidar de si e dos irmãos menores, visto que a mãe dependente de álcool estava incapacitada de exercer o cuidado. No contexto desse estudo, a família extensa, particularmente a avó da participante, exerceu a função parental de cuidado. Interessados no impacto da violência e/ou negligência parental engendrada pelo consumo do dependente de álcool, Lopes, Maia e Lopes (2019) investigaram as crenças de uma criança, filha de alcoolista. Os autores identificam na participante uma visão de si como incapaz, rejeitada e impotente e uma visão do outro como inacessível, exigente, traiçoeiro e agressivo. O predomínio de emoções negativas como traços de ansiedade e depressão, associados às crenças de desamparo, menos valia e desamor comunicam sobre o tipo de sofrimento emocional vivido por esse público.

Silva (2016) identificou problemas emocionais como timidez e baixa autoestima em crianças no jardim de infância que são filhas de alcoolistas. Já Singh (2017) encontrou menores índices de autoeficácia, autoestima e bem-estar emocional. A despeito do sofrimento vivido, muitos filhos almejam estabelecer um vínculo significativo com o progenitor dependente de álcool. Possivelmente, a ambivalência em relação ao pai e/ou mãe alcoolista, que ora é agressivo e/ou distante, ora é acessível e/ou próximo afetivamente seja a justificativa para que os adolescentes entrevistados por Albuquerque, Heimerdinger e Rodrigues (2016) tenham manifestado ideias divergentes em relação à figura parental dependente de álcool, na medida em que uns expressam o desejo de cuidar do progenitor enquanto outros só viam a possibilidade de uma vida autêntica e feliz se morassem longe da família de origem.

Souza e Carvalho (2012) reconhecem que o sofrimento vivido por filhos de alcoolistas na infância e adolescência continua a produzir ressonâncias afetivas na vida adulta, favorecendo, inclusive, que se tornem alcoolistas. Em contrapartida, Silva, Silva e Vaz (2013) identificam características de resiliência nesse grupo, as quais resultam em proteção emocional, tais como o temperamento afetuoso, a persistência nos objetivos, a responsabilidade com tarefas cotidianas e atitudes positivas com a vida. Além disso, diante de situações de conflito, ansiedade e medo, a capacidade de se distanciarem de vivências críticas possibilita uma ressignificação das experiências traumáticas. 
Diante deste contexto de intenso sofrimento que caracteriza o cotidiano de famílias marcadas pelo alcoolismo e sua repercussão sobre a saúde mental e relacionamentos interpessoais de seus membros, focalizamos, neste estudo, o percurso emocional de Rosa Vermelha para encontrar a si mesma e viver uma vida autêntica.

\section{MÉTODO}

Politzer (1928/1998) elaborou uma crítica aos fundamentos da psicanálise pontuando a contradição entre dois discursos presentes na obra freudiana: primeiro, o que se refere à metapsicologia e os constructos positivistas de que Freud se serviu para explicar o funcionamento psíquico humano; e segundo, quando Freud prioriza a escuta da experiência vivida tal como é narrada por seus pacientes. De acordo com Politzer, Freud se afasta de uma psicologia concreta quando compreende e/ou explica o ser humano através de conceitos metapsicológicos que recortam o drama do indivíduo do contexto em que vive.

A advertência de Politzer (1928/1998) quanto à especulação freudiana, que mais tarde encontra eco na proposta de Bleger (1963/1984) sobre uma psicanálise fundamentada nas vivências humanas, aliada à defesa de Herrmann (1979/2001) de que o método psicanalítico é o que caracteriza a psicanálise e não as teorias e técnicas que dele advêm, fundamentam a estrutura deste estudo. Por essa razão, tomaremos Winnicott, cuja proposta psicanalítica se afasta da metapsicologia e dos conceitos positivistas (Fulgêncio, 2015), como interlocutor para nossa compreensão da experiência emocional de filhos de dependentes de álcool.

Interessados em compreender as vivências dos filhos de alcoolistas fizemos uso de narrativas como recurso metodológico que se afina às reflexões de Politzer (1928/1998) e de Bleger (1963/1984) sobre a psicanálise como psicologia centrada no drama concreto do indivíduo. Com Benjamin (1936/1996) e Ricoeur (1991) sabemos que o processo de narrar experiências possibilita que se possa (re)viver imaginativamente uma experiência e, deste modo, pensá-la para elaborar novos sentidos. E, nesse sentido, a articulação desses argumentos fortalece nossa opção metodológica pelo uso da narrativa dado o seu potencial gerador de sentidos afetivo-emocionais ao criar uma cena imaginativa em que a vivência e a reflexão se entrelaçam.

$\mathrm{Na}$ presente pesquisa utilizamos dois recursos narrativos psicanaliticamente orientados para acessar a experiência emocional de filhos de dependentes de álcool. A Narrativa Interativa (NI) é o primeiro deles e consiste em uma história ficcional elaborada pelo pesquisador tendo em vista um determinado grupo de participantes e o fenômeno que pretende investigar - em nosso caso a experiência emocional de ser filho de alcoolista. A NI se interrompe em um determinado ponto da trama para que cada participante a complete de modo espontâneo e criativo (Winnicott, 1971/1975b). Em função do caráter lúdico e vivencial da NI, ao escrever o desfecho da história o participante comunica suas fantasias, memórias, crenças, 
angústias e defesas que estão relacionadas à experiência em investigação. Posteriormente, ele é convidado pelo pesquisador a associar livremente sobre o tema, o que viabiliza nova narração de afetos e histórias vividas, assim potencializando a produção de sentidos afetivo-emocionais.

Inspirada no Jogo do Rabisco de Winnicott (1971 e criada por Granato e AielloVaisberg (2013), a NI cumpre uma função dialógica e o estabelecimento de um contexto lúdico para a expressão imaginativa dos participantes durante as entrevistas de orientação psicanalítica. Para elaborá-la é necessária uma imersão no tema investigado, o que é possível pela busca de literatura científica e/ou experiência clínica dos pesquisadores na área. É importante que o texto da NI seja vivencial para que o leitor/participante imagine a cena, identifique-se com os personagens e sinta-se convidado a participar de uma interação. Atendendo à recomendação de Stake (2011) e Flick (2013) quanto a ampliar o rigor na pesquisa qualitativa, discutimos com os demais integrantes do grupo de pesquisa a primeira versão da NI e avaliamos o seu impacto emocional e sua pertinência à questão de pesquisa. Após esta discussão, que visa não só a obtenção de um consenso, mas também ampliar a produção de sentidos, novas versões são elaboradas até que se chegue à NI aprovada em função de seu potencial para comunicar a experiência vivida e permitir diferentes possibilidades de desfechos para a trama.

O segundo recurso narrativo utilizado neste estudo foi a Narrativa Transferencial (NT). Criada por Aiello-Vais Berg, Machado, Ayouch, Caron, Beaune (2009), a NT é um procedimento de registro vivencial que permite a análise de seu material narrativo em termos das relações transferenciais que caracterizam cada encontro. Fundamentada no paradigma intersubjetivo (Silva, 1993) de acordo com o qual a presença do pesquisador é também tomada como objeto de análise, a NT também coloca em cena as emoções, pensamentos e sensações do entrevistador. Assim como a NI que abre para o participante uma gama de desfechos, a NT oferece ao leitor uma possibilidade de reflexão imaginativa, pois para compreender as experiências dos participantes terá que recorrer às próprias vivências ou viver uma nova experiência na leitura (Ordem, 2018).

Finalmente, ressaltamos que ambos os recursos da NI e NT dialogam com o método psicanalítico que se fundamenta na articulação entre a associação livre do participante e a atenção flutuante do pesquisador. Durante a entrevista o participante é convidado a associar livremente por meio da NI, seja na construção do desfecho da história, seja no relato pessoal de suas vivências. Já o pesquisador se coloca em estado de atenção flutuante durante a entrevista e na redação da NT, o que the permite compreender o conteúdo emocional dos relatos dos participantes. Após a conclusão da escrita da NT, o pesquisador a discute novamente com seu grupo de pesquisa com o intuito de obter o consenso sobre os sentidos desvelados. Segundo Aiello-Vais Berg et al. (2009), é nesse momento que o pesquisador pode estabelecer os aspectos inconscientes da experiência emocional investigada e assim construir uma discussão fundamentada em uma 
psicanálise que privilegia as vivências humanas em detrimento de uma psicanálise metapsicologia que está alienada do viver.

\section{PARTICIPANTES}

Embora tenham sido entrevistados 12 filhos adultos de alcoolistas como participantes voluntários de nossa pesquisa, neste estudo apresentamos o caso de Rosa Vermelha que se tornou emblemático do sofrimento daqueles que conviveram com o alcoolismo dos pais. Com esse recorte objetivamos compreender de maneira aprofundada uma experiência coletiva por meio de um dos casos individuais.

A participante Rosa Vermelha tem 32 anos, é casada, mãe, cursou o Ensino Médio, sua condição socioeconômica é baixa e exerce a função de motorista. Conviveu com o progenitor na mesma casa até os 21 anos de idade. A inspiração para a escolha de seu nome fictício provém da estética espinhosa de seu drama e do vermelho-sangue que tinge seu relato sobre as agressões físicas que testemunhou em sua infância e adolescência.

\section{INSTRUMENTOS}

Foi utilizada uma Narrativa Interativa (NI) cuja trama ficcional apresenta o drama de um filho de alcoolista e de sua mãe que aguardam com ansiedade a chegada do pai. A NI se interrompe em um momento de clímax para que o participante a complete dando-lhe um desfecho.

\section{PROCEDIMENTOS}

Após a aprovação do Comitê de Ética de uma universidade privada do interior do estado de São Paulo sob o parecer $n^{\circ} 2.396 .129$, o pesquisador entrou em contato com a sede dos Grupos Familiares de Alcoólicos Anônimos (ALANON) do Brasil que divulgou dentre os seus membros a presente pesquisa e o contato telefônico do pesquisador que faria as entrevistas para os potenciais interessados. Em caráter voluntário, 12 filhos adultos de alcoolistas entraram em contato com o pesquisador para agendar entrevistas individuais que ocorreram ou na residência do participante ou em sala cedida pela ALANON nas sedes dos grupos de mútuaajuda da cidade do participante. No caso de Rosa Vermelha, a entrevista durou 80 minutos, tendo sido informada do objetivo e método da pesquisa e esclarecido suas dúvidas durante a leitura em conjunto do Termo de Consentimento Livre e Esclarecido. Em seguida, o pesquisador apresentou a NI, deixando a participante à vontade para acrescentar o seu desfecho. Compreendendo que a NI é um recurso lúdico-dialógico (Winnicott, 1971/1975a) na entrevista de orientação psicanalítica que visa facilitar a comunicação afetivo-emocional, observamos que apenas um dos participantes preferiu dispensar o recurso e narrar diretamente a sua história com o pai alcoolista. Os demais participantes, como Rosa, fizeram um uso criativo da NI expressando-se de forma autêntica. Após a escrita do desfecho da NI, o 
pesquisador convidou Rosa Vermelha a refletir livremente sobre as impressões, sentimentos e/ou memórias que a NI pudesse ter constelado.

A entrevista com Rosa Vermelha, como as demais, foi registrada sob a forma de Narrativa Transferencial (NT) objetivando descrever o encontro em suas tonalidades afetivas, comunicadas pelo conteúdo e estilo do relato da participante e pelos movimentos transferenciais identificados. O material narrativo obtido pela NI e NT foi tomado para análise psicanalítica que resultou na identificação de quatro campos de sentido afetivo-emocional (Herrmann, 1979/2001) mediante leitura flutuante e obtenção de consenso no grupo de pesquisa (Stake, 2011). Como o campo se estrutura como eixo em torno do qual se organizam determinados sentidos da experiência vivida pelo participante, cada campo recebeu um título emblemático que alude à dramática da experiência narrada pelo participante.

\section{RESULTADOS}

Conforme o objetivo deste estudo, nos deteremos sobre o relato de Rosa Vermelha sobre sua experiência como filha de alcoolista, dado o seu caráter emblemático, recorte que nos permitirá uma maior exposição do material narrativo respeitando os limites desta publicação. Destacamos que na discussão também faremos uso dos relatos dos demais participantes desta pesquisa. É válido ressaltar que o progenitor dependente de álcool de todos os participantes era o pai.

\section{NARRATIVA INTERATIVA APRESENTADA AOS PARTICIPANTES}

Era noite e Gilberto estava em seu quarto estudando, revendo as anotações que tinha feito das aulas do curso técnico. Sentia-se animado com as aulas e enquanto lia os textos e refazia os cálculos matemáticos, escutava as músicas que tocavam em seu rádio. Às vezes, ao som da música, Gilberto devaneava, recordando-se do que tinha lhe acontecido durante o dia. Tantas pessoas importantes que tinha conhecido recentemente ... Fazia projetos para o futuro e se imaginava em novas situações e experiências.

-Mas que fome!!! - pensou o rapaz. Fazia horas que não se alimentava em função da dedicação aos estudos. Nesse momento, dirigiu-se à cozinha para jantar; mas antes passou pela sala, onde estava a sua mãe, Maria Amélia. Gilberto viu a mãe sentada no sofá, tranquila, assistindo à televisão. Depois, pegou um prato na cozinha e começou a explorar o que tinha no fogão, ficando surpreso e bem contente com a carne de panela com batata.

De repente, a cachorra começou a latir e Gilberto se lembrou de que seu pai, Osvaldo, estava fora de casa, bebendo. "Será que ele chegou?!" - pensou o moço, apreensivo. Naquela hora, Maria Amélia se levantou do sofá e foi até a cozinha, ao encontro do filho. Gilberto conhecia aquela expressão no olhar da mãe.... Sim, 
Osvaldo tinha acabado de chegar em casa, estacionando o carro em cima da calçada.

Gilberto percebeu seu coração mais acelerado e, deixando o prato na mesa da cozinha, acompanhou a mãe até a entrada da casa para receber o pai. Quando Gilberto abriu a porta....

\section{NARRATIVA TRANSFERENCIAL SOBRE O ENCONTRO COM ROSA VERMELHA}

Convidada a criar um desfecho para a história do personagem Gilberto (NI), Rosa Vermelha logo se colocou à vontade e começou a escrever, permanecendo em uma espécie de silêncio contemplativo que lhe permitiu uma escrita concentrada, a qual transcrevemos em sua íntegra:

"Viu seu pai totalmente alcoolizado sem forças e sem equilíbrio. Foi ao seu encontro para ampará-lo e levá-lo para dentro de casa. Acomodou seu pai no sofá da sala e voltou para o carro, para estacionar devidamente. Vendo o estado de sua mãe, levou-a para a cozinha, tentando deixá-la o mais calma o possível para não começar a discussão, porque toda vez que seu pai estava alcoolizado ficava violento, e sua mãe não aguentava passar por esta situação e ficar calada.

Gilberto aguentava passar tudo calado, para não aborrecer sua mãe. Queria sempre manter o lar o mais harmonioso possível, porém nem sempre ele conseguia. Pedia para sua mãe resolver a situação se separando de seu pai, mas ela respondia que não era dessa maneira que as coisas se resolviam. Muitas vezes, Gilberto culpava sua mãe, por ela também facilitar as bebedeiras de seu pai. Tinha vezes que Gilberto enfrentava seu pai, e acabava em violência, ele queria mudar o jeito e sua convivência, mas sempre acabava derrotado.

Na mente de Gilberto, seu pai não era doente, mas agia desta maneira porque não amava sua família e queria puni-los com essa atitude. Gilberto não sentia pena de seu pai, ele só queria que ele parasse de ter estas atitudes e respeitasse sua mãe, que fazia de tudo para agradá-lo porque o amava.

O que resta agora para Gilberto é esperar passar a bebedeira do pai e tentar conversar com ele, pondo sua emoção, coragem e respeito, por mais difícil que seja. Já com sua mãe, precisa mantê-la em equilíbrio, para que não tente impor suas emoções e discutir com uma pessoa que não vai escutar, mas vai piorar cada vez mais até chegar à agressão.

Ser filho de alcóolico não é fácil, você fica entre a cruz e a espada, tentando manter o equilíbrio e a harmonia".

Tendo finalizado sua NI e convidada a compartilhar sua experiência de escrita, Rosa Vermelha desabafa: "Eu gostei de escrever, achei que foi bom porque a história do Gilberto é bacana para ilustrar a vida dos filhos de alcoolistas. Mas eu ainda nem comecei, tenho tanta coisa para te contar!" 
Dando continuidade ao seu relato, agora de modo verbal, Rosa Vermelha decidiu falar primeiramente sobre o seu pai, descrevendo como este chegava em casa quando estava alcoolizado, como se estivesse retomando a NI do mesmo ponto em que a interrompera:

"Na minha casa, o alcoolista era o meu pai, e ele bebeu desde que eu me conheço por gente. A questão é que ele saía muito para ir ao bar... quase todos os dias, eu e minhas irmãs tínhamos muito medo do momento em que ele chegaria em casa, pois geralmente víamos cenas de violência em que ele era o agressor. Horrível! Meu principal terror, assim como das minhas irmãs era chegar em casa e deparar com ele espancando a nossa mãe. Nós já vimos isso e ficamos desesperadas! Numa das ocasiões, totalmente paralisadas, e não sabendo o que fazer para impedir aquilo, ficamos chorando uma noite inteira".

Rosa olhou para o chão, tentando disfarçar o choro que sem aviso a assaltava. Após um suspiro, prosseguiu sua história, descrevendo situações de violência que, ainda criança, presenciara na família paterna. Além de seu pai, todos os seus tios e tias paternos eram alcoolistas, bebiam diariamente e sofriam com problemas financeiros e com suas atitudes impulsivas. Rosa conclui que a educação se dava "por meio do apanhar" (sic), pois se alguém apanhava injustamente os parentes logo vinham justificar: "Se apanhou, é porque mereceu!" (sic).

A participante selecionou duas das mais vívidas lembranças que conservava de sua infância: uma, quando aos quatro anos de idade presenciou o pai dando um tapa no rosto da mãe; outra, que lhe era particularmente dolorosa, quando a avó paterna idosa e doente, cujo cuidado fora negligenciado, sofria agressões frequentes dos filhos alcoolistas.

A avó de Rosa ficava aos cuidados de uma das filhas, a que morava na mesma casa e frequentava diariamente os bares, chegando à noite em casa alcoolizada e alterada. Diante das necessidades da avó idosa e doente, a tia se impacientava e a agredia, deixando-Ihe hematomas pelo corpo. Como a avó era diabética, começou a ter problemas na cicatrização das feridas. O pai e os tios de Rosa criticavam a avó pelo agravamento da sua situação e, irritados, tornavam-se agressivos. A participante se recorda de como se impressionava com as marcas de sangue na casa da avó e com os cachorros bravos que ali viviam e pareciam querer morder todo e qualquer visitante. No entanto, os mesmos cães lambiam as feridas da senhora idosa.

"Essa família sempre teve marcas da violência! Meu pai apanhou demais na infância, viu muitas coisas e foi um menino judiado... eu até entendo, em certa medida. O pai dele era alcoolista e batia na esposa e na própria mãe! Sabe, muita dor envolvida na vida de todos. E, nesse contexto, eu ficava assustada e sem entender. Bem pequena, ao visitar a minha avó sentia uma angústia ... ver aqueles cachorros bravos e as marcas de sangue na parede e no chão ... parecia que eles iriam arrancar um pedaço da gente!" 
A participante explicou que antes acreditava que o pai bebia e era agressivo porque ela, suas irmãs, ou a mãe deviam ter "feito algo errado, descumprido alguma regra" (sic). O sentimento de culpa e a ansiedade se intensificavam porque elas não conseguiam identificar nem regra nem motivo que justificasse as bruscas mudanças do humor paterno. A ambiguidade da figura paterna a exasperava: quando ele estava sóbrio, comportava-se de modo educado, apesar de distante e lacônico, sendo estimado por colegas de trabalho e por outras pessoas da comunidade; quando embriagado, sua conduta era manifestamente agressiva, destacando-se as humilhações verbais e físicas contra os familiares. Para Rosa, "o pai, às vezes, parecia ser duas pessoas completamente diferentes" (sic).

Foram muitas as situações em que o pai alcoolizado provocou conflitos no ambiente de trabalho, mobilizando a esposa e as filhas para socorrê-lo. Em uma destas, o pai de Rosa chegou a entrar em coma alcoólico no serviço, o que implicou resgatá-lo com urgência para o hospital mais próximo. O medo que ele morresse e a tristeza pelo comportamento recorrente e arriscado do pai desanimavam a família a qual se via impotente.

Rosa Vermelha enumerou algumas das estratégias que fez uso durante a vida para minimizar o impacto do alcoolismo do pai ou, quem sabe, curá-lo. A primeira foi tentar identificar os motivos ou regras quebradas pela família, conforme sua concepção sobre o que desencadeava as crises no pai, estratégia que se mostrou pouco eficaz na busca de um sentido para o que estava sendo vivido. Outra estratégia foi quando a adolescente Rosa, cansada dos conflitos familiares, decidiu se livrar de todas as garrafas e latas de bebida que o pai guardava em casa, derramando-as no vaso sanitário e jogando os recipientes no lixo do banheiro. A consequência foi desastrosa: Rosa levou uma surra que a deixou ferida física e psiquicamente. $O$ relato emocionado que a participante fez da cena do pai tentando sufocá-la no banheiro onde tentara ingenuamente se livrar do problema do progenitor produziu novo impacto no pesquisador que conduzia a entrevista.

As cenas de humilhação e espancamento não eram exclusividade do pai, sendo também protagonizadas pelos tios, tias e primos. Hoje, os parentes de Rosa mantêm uma atitude distante, porém marcada por uma hostilidade implícita nas cobranças e discursos. Ao longo do tempo, como última estratégia, Rosa procurou afastar-se da influência familiar, selecionando o que lhe fazia bem de forma a evitar dissabores desnecessários.

Hoje, já adulta, casada, morando em outra cidade e animada com a nova profissão, a participante se declara orgulhosa por estar atuando na mesma área de trabalho do pai. A despeito das dores e mágoas, Rosa sente muito carinho pelo progenitor, orgulha-se dele e manifesta o desejo de reaproximação. Satisfeita, conta que, em função do novo emprego, estava conseguindo conversar mais longamente com o pai, ocasião em que compartilhavam conhecimento e experiência profissional.

À medida que o relato de Rosa sobre sua relação com o pai alcoolista ia deixando o passado e alcançava o presente, o choro foi sendo substituído por sorrisos e até 
risadas, comunicando um clima emocional mais leve. Rosa reconhece que o pai the ensinou "como fazer as coisas por mim mesma, sem depender de um homem para uma atividade" (sic). Rosa aprendeu tarefas que são geralmente ensinadas aos homens, na nossa cultura, tais como arrumar um chuveiro, consertar um problema no motor do carro, levantar e rebocar uma parede com tijolo e argamassa, dentre outras. Esse aprendizado Ihe foi muito significativo, visto que the ensinou um valor que considera inestimável: ser independente.

A participante conclui que a convivência com o pai alcoolista foi ressignificada na vida adulta, o que hoje lhe permite visitá-lo e conversar sobre o passado, inclusive sobre as cenas de violência vividas em sua infância. Hoje, Rosa Vermelha consegue até brincar com esse assunto, porém sem ignorar os efeitos da violência e o percurso que foi necessário para sua superação.

"Hoje quando eu o visito, brinco com papai que se ele tentasse me bater agora ... ah, apanharia feio!!! Daí ele me responde, também brincando, que nem se atreveria porque sabe que sou mais forte que ele. Nós falamos sobre isso brincando e rindo, mas não foi do dia para a noite porque exigiu tempo para brincar sobre esse assunto complicado. Foi difícil conseguir rir disso ..."

Quando a entrevista caminhava para o seu encerramento, Rosa selecionou uma última imagem para ilustrar suas conquistas na convivência com o pai. Enquanto a participante e seu esposo conversavam, via Skype, com o pai de Rosa, alcoolizado, começou a achá-lo engraçado sem a dentadura. A participante brincou com o pai sobre a sua boca sem dentes e ambos riram. O que mais surpreendeu Rosa foi o "Eu te amo! Eu amo vocês!" dito de forma tão espontânea pelo pai. Para Rosa aquelas palavras eram preciosas como diamantes.

\section{DISCUSSÃO}

Como resultado da análise interpretativa do material narrativo produzido por Rosa, elaboramos quatro campos de sentidos afetivo-emocionais que subjazem à experiência vivida por Rosa e pelos demais participantes da pesquisa. Conscientes de que abordamos facetas de experiências cuja totalidade é transbordante e escapa à nossa compreensão, a despeito da adequação do método ao objeto deste estudo, elaboramos os seguintes campos: "Marcas da Violência"; "Desejo Soberano", "Sobrevivendo ao Caos" e "De volta à minha vida!".

\section{CAMPO 1: MARCAS DA VIOLÊNCIA}

O presente campo de sentidos afetivo-emocionais comunica a violência que marca a convivência dos filhos com o progenitor alcoolista. As memórias de infância de Rosa são carregadas de violência e medo. O humor flutuante do pai e a expectativa de agressão quando este chegasse do bar deixavam a participante e sua família em constante estado de alerta. Descreveu uma cena em que ela e as irmãs, ainda crianças, choravam em desespero ao verem a mãe ser espancada pelo pai e incapaz 
de se defender. Discorreu sobre um cotidiano marcado pelo medo, pela ameaça de que o menor gesto desencadeasse a hostilidade paterna e pusesse a perder a estabilidade conquistada com tanto esforço, ainda que fosse uma falsa estabilidade.

Rosa refere a violência como um dos componentes mais destrutivos do relacionamento interpessoal que se estabelece em famílias de dependentes de álcool, o que é confirmado pelos demais participantes da pesquisa em cujos relatos associavam as agressões físicas e/ou psicológicas vividas como marcas subjetivas que continuavam a reverberar na vida adulta. Diferentes estudos mostram que a violência intrafamiliar tem impactos negativos na subjetivação dos indivíduos, no sentido de que as memórias traumáticas favorecem medos e dificuldades interpessoais, além da baixa autoestima e baixa autoeficácia oriundas de uma convivência abusiva (Hermel \& Drehmer, 2013; Stefanini, Juan-Martínez, Silva \& Farinha, 2019).

À luz da descoberta de Freud sobre a potencialidade heurística do método psicanalítico (Herrmann, 1971/2001) e da riqueza das metáforas inconscientes que estão presentes nas associações livres (Zanello \& Martins, 2010), nos debruçamos sobre as imagens utilizadas por Rosa para comunicar o impacto da violência intrafamiliar na constituição de sua subjetividade.

Quando Rosa compartilha uma memória infantil sobre a casa de sua avó paterna, a referência aos cachorros bravos que "mordem e arrancam pedaços das pessoas" (sic) chama a nossa atenção produzindo o efeito contratransferencial imediato de sermos transportados para o lugar de testemunhas do horror de dentes que devoram e derramam sangue. A participante descreve uma cena de violência canibalística, em que todos os familiares apanham e/ou são desqualificados moralmente, de modo que a cada ofensa ou tapa corresponde uma mordida capaz de produzir feridas narcísicas e arrancar pedaços do próprio self. Da narrativa de Rosa também emerge a associação inconsciente entre os cães ferozes e seu pai quando está alcoolizado e irascível. Entretanto, observamos que a hostilidade deste pai que tanto a apavorava vem sendo contida pelo tempo, pelo envelhecimento, cumprindo o seu papel de "amansador de feras". Hoje Rosa consegue conversar e até brincar com o pai sobre a violência vivida no passado, tendo em vista a perda da potência paterna diante de uma filha que agora tem recursos para se impor. Finalmente, destacamos a cena em que Rosa está conversando com o pai via Skype e percebe que ele está sem a dentadura. A participante se diverte com a situação e brinca com o pai sobre sua aparência - a boca sem dentes - em uma espécie de atualização da figura paterna da infância para a de um "velho cão sem dentes" que já não consegue morder ninguém.

A metáfora do cão feroz inclui a resolução do conflito, indicando que a aproximação entre pai e filha só foi possível quando a agressividade deixou de ser uma ameaça, permitindo a ressignificação do vivido e a comunicação do amor parental. Não é à toa que para Rosa as palavras de carinho de seu pai soaram 
preciosas como diamantes, atestando o impacto da violência parental na inibição das expressões espontâneas de afeto entre pais e filhos.

Além dessas imagens psíquicas carregadas de afetos, sendo a metáfora inconsciente uma das formas possíveis do psiquismo conter e significar o vivido, observamos outras marcas da violência parental nos filhos de alcoolistas. Destacamos que as memórias traumáticas/cenas de violência impactam na estruturação do indivíduo, particularmente na sua compreensão de mundo e de relacionamentos interpessoais. É possível supor, a partir dos relatos colhidos, que filhos de alcoolistas que presenciaram cenas de violência tenham dificuldades para confiar nas pessoas, revivendo transferencialmente essas experiências traumáticas em outras relações humanas. Os estudos de Lopes, Marcon e Deceraso (2015), Teixeira et al. (2015) e Albuquerque et al. (2016), corroboram essa hipótese ao mostrar que a violência vivida na família do alcoolista corrói o sentimento de segurança e confiança dos familiares.

Recorremos a Winnicott (1962/1990) e sua teoria da provisão ambiental para compreender que a previsibilidade no cuidado infantil permite que o indivíduo desenvolva os sentimentos de segurança e confiança no ambiente. Filhos de alcoolistas convivem ao longo do desenvolvimento com ambientes imprevisíveis, conforme relato emblemático de Rosa Vermelha. Frente a um pai alcoolizado com humor volátil e potencialmente violento, os filhos não encontram o solo previsível para se sentirem seguros no âmbito familiar. A insegurança e a desconfiança são marcas subjetivas da violência que impactam as relações familiares, sociais e laborais na vida adulta dos filhos, atingindo sua autoestima e os deixando à mercê de pensamentos negativistas sobre a própria capacidade.

O relato de Rosa nos leva a ponderar sobre essa "cultura da violência" que permeia as condutas familiares e naturaliza práticas abusivas, cujo impacto emocional resulta no medo e no silêncio sobre a violência intrafamiliar que, no entanto, continuam a ressoar ao longo de gerações (Colossi, Marasca, \& Falcke, 2015; Feijó et al., 2016, Ferraboli et al., 2015). A transmissão intergeracional da violência pode ser observada na narrativa de Rosa quando afirma que todos os conflitos familiares eram resolvidos por meio do "bater" e do "apanhar". Dependendo da história do indivíduo, dos relacionamentos interpessoais e das condições concretas de existência, a violência pode ser o único modelo oferecido pelos pais. É possível que diante desta escassez de modelos o indivíduo tenda a reproduzir, na vida adulta, a violência como estratégia para a resolução de problemas. Tal fato pressupõe a dificuldade de o indivíduo recorrer ao diálogo e a flexibilidade na busca de novas soluções para as dificuldades interpessoais, o que pode ser observado nas condutas dos tios e do pai de Rosa que também foram filhos de alcoolistas e sofreram violência.

No outro extremo, os filhos podem não desenvolver uma assertividade necessária aos relacionamentos interpessoais, em função de uma história de submissão à violência parental que não lhes permite estabelecer fronteiras/limites ao outro, 
desencadeando novo sofrimento. Somado a isso, podemos supor que o impacto no sentido de autovalor e de independência emocional dos filhos de alcoolistas pode favorecer carências afetivas que interferem nas relações interpessoais na vida adulta.

Finalmente, destacamos como última marca subjetiva engendrada pela violência parental: o ódio ao progenitor que agride. Embora esse ódio não encontre expressão emocional cuja vazão produziria efeitos catárticos, segue reprimido, por medo de retaliação parental e social, mas chega a produzir sentimento de culpa nos filhos pelo ódio ao pai agressor. De todo modo, trata-se de um tema complexo que merece novas investigações.

\section{CAMPO 2: DESEJO SOBERANO}

Este campo de sentidos afetivo-emocionais desvela a presença de um pai alcoolista autoritário que ocupa o centro das atenções familiares e que exige que as suas demandas e/ou desejos sejam considerados soberanos em relação às necessidades do cônjuge e dos filhos. Rosa precisou se submeter aos caprichos de um pai violento, condição também referida por outros participantes que descreveram como as famílias acabam se adaptando ao despotismo do alcoolista, protegendoo das frustrações que, de outra forma, ocasionariam novas ondas de violência.

Rosa Vermelha também nos informa sobre como a dinâmica das relações familiares se estrutura em torno do consumo de álcool de seu progenitor. Rosa vivia uma angústia cotidiana frente ao consumo de álcool do pai, agindo como uma mãe preocupada (Winnicott, 1956/2000) com as demandas/necessidades de um paibebê. Observamos este tipo de expediente nas tentativas de Rosa cuidar do progenitor, socorrendo-o em diferentes situações de intoxicação alcoólica ou quando tentou curá-lo jogando fora todas as bebidas alcoólicas, possivelmente motivada pela crença de que a presença do produto seria o gatilho para o consumo.

O papel ocupado pelo alcoolista como centro das atenções e preocupações dos familiares que passam a se submeter aos seus desejos na medida em que ignoram as suas próprias necessidades é o que nos parece configurar como as sucessivas invasões ambientais ao self, capazes de mobilizar defesas psíquicas para a sobrevivência emocional (Winnicott, 1960/1990). É nesse ambiente ameaçador, frente ao qual o gesto espontâneo não encontra acolhida, que vemos proliferar os sentimentos de impotência, insegurança e medo que comprometem o desenvolvimento emocional saudável.

Rosa nos ensina que quando a família se torna refém dos desejos do alcoolista, somente a distância geográfica do dependente de álcool é vista como solução definitiva que interrompe as intrusões ambientais e inaugura a possibilidade de retomada da continuidade de ser (Winnicott, 1969/1993). Ao se casar e mudar de cidade, afastando-se dessa relação transferencial abusiva, a participante pôde retomar o viver interrompido, o que lhe permitiu elaborar as experiências da 
infância/adolescência e estabelecer uma base segura para o desenvolvimento do self.

Assim compreendemos que os filhos de alcoolistas comunicam a necessidade de um ambiente previsível, seguro e confiável como base para a manutenção de uma continuidade existencial. É possível que Rosa tenha encontrado no seu relacionamento conjugal a sustentação emocional que precisava para voltar a se sentir viva e real nas próprias experiências (Winnicott, 1960/1990).

\section{CAMPO 3: SOBREVIVENDO AO CAOS}

O presente campo de sentidos afetivo-emocionais aborda a experiência de Rosa Vermelha ao se sentir convocada a resolver os conflitos familiares e a buscar explicações possíveis para as experiências traumáticas como forma de responder à angústia deflagrada pela conduta abusiva do pai alcoolista. Portanto, tal campo revela o que nos parece ser um conjunto de estratégias defensivas utilizadas por filhos de dependentes de álcool a fim de preservar e desfrutar do sentimento de continuidade de ser que lhe está sendo pouco a pouco roubado pelas repetidas invasões da realidade familiar (Winnicott, 1960/1990).

Na NI de Rosa observamos esse tipo de expediente, quando a participante atribui ao personagem Gilberto uma atitude de entrega à restauração do equilíbrio e da harmonia do lar, assumindo o papel de cuidador dos próprios pais. Neste caso, observamos que o filho do alcoolista precisa se ausentar de seu lugar social como filho e assumir responsabilidades que, na cena familiar, seriam usualmente atribuídas aos progenitores. Chama, ainda, a nossa atenção a renúncia do filho, via personagem Gilberto, ao próprio cuidado e a aceitação passiva da tarefa parental, sem qualquer traço de revolta, como se diante de tanto desamparo só lhe restasse entorpecer o próprio self para cuidar/proteger o pai alcoolizado.

Em função do desfecho da NI de Rosa, compreendemos que este foi também o seu papel familiar, ficando "entre a cruz e a espada" (sic) para exercer as funções parentais e tentar "manter o equilíbrio"(sic) da convivência familiar. Os demais participantes da pesquisa ecoaram essa conduta de Rosa, o que também foi observado em outros estudos científicos, como o de Silva, Silva e Vaz (2013) e o de Santos et al. (2015). Ao assumir o papel de conciliador/mediador da paz familiar, o filho de alcoolista visa proteger a própria continuidade de ser, base para o seu desenvolvimento emocional (Winnicott, 1969/1993). Diante de um histórico de invasões ambientais vividas na família, o filho tenta assumir defensivamente o controle dos conflitos para tentar solucioná-los e, desse modo, frear a frequência e a intensidade das invasões. Contudo, como esse controle é defensivo e precário, mantém a situação de vulnerabilidade emocional do indivíduo que continua correndo o risco de se desorganizar psiquicamente sempre que se extrapole as suas capacidades de contenção e elaboração do conflito (Winnicott, 1963/1994).

Observamos essa tentativa de preservar a integridade do self quando Rosa busca explicações plausíveis para a violência e o uso abusivo de álcool pelo progenitor. 
Diante da imprevisibilidade paterna que comprometeria qualquer possibilidade de integração das experiências em um continuum existencial, Rosa elabora teorias explicativas na esperança de encontrar um sentido para o caos vivido e, assim, diminuir o impacto da invasão ambiental. Tais estratégias de contenção de vivências caóticas, não só se mostraram ineficazes como produziram sobrecarga emocional pelo sentimento de culpa despertado pelas teorias familiares que justificavam a violência parental pelo "mau comportamento" dos filhos.

O prejuízo que o alcoolismo parental acarreta para a saúde mental dos filhos não se restringe à negligência quanto ao autocuidado para atender as demandas dos familiares. Compreendemos que, diante da insuficiência do ambiente familiar na provisão de cuidados, os filhos de alcoolistas fazem uso de defesas que, se por um lado possibilitam o enfrentamento da situação, de outro, inibem uma experiência criativa e integrada, pois a ação sobre o mundo se torna reativa e advinda de um falso self que protege o verdadeiro e permite a mera sobrevivência (Winnicott, 1960/1990).

Winnicott (1969/1993; 1971/1975b) faz uma distinção entre o sobreviver e o viver, argumentando que a satisfação de necessidades básicas como alimentação, abrigo e segurança permitem que o indivíduo confie no ambiente e ouse viver suas experiências de modo criativo, isto é, carregadas de sentido pessoal. O viver winnicottiano implica a possibilidade de o indivíduo criar o mundo ao mesmo tempo em que o encontra, dotando de sentido sua existência. Contudo, a violência que modulou a experiência emocional de Rosa e dos demais participantes deste estudo comprometeu a confiabilidade do ambiente familiar, na medida em que negligenciava necessidades básicas de segurança e respeito e convocava estratégias de sobrevivência emocional. No lugar de um ambiente suficientemente bom que favorecesse o desenvolvimento humano, os participantes viveram a disfuncionalidade na comunicação, na divisão de tarefas e/ou papéis familiares, além da ansiedade, do medo e da dor física e emocional.

Refletimos sobre a adequação de potenciais intervenções destinadas a filhos de alcoolistas que observassem esse movimento defensivo quando a segurança e a confiança foram abaladas para sempre. Inspirados em Winnicott (1969/1993) que enfatiza o manejo sensível do terapeuta, ponderamos sobre a sintonia entre o cuidado profissional destinado a esse público e sua necessidade de um ambiente previsível e confiável para sentirem-se seguros, mesmo na vida adulta. O terapeuta que oferece aos filhos de alcoolistas essa sustentação será capaz de acolher o seu gesto espontâneo e poderá trabalhar o sentido das estratégias defensivas na história desses indivíduos, ajudando-os a elaborar as vivências traumáticas e suas repercussões na vida adulta. Considerando que para o bebê a integração do caos possibilita a emergência da gestualidade espontânea (Winnicott, 1990/1962), apostamos que a elaboração/ressignificação do caos vivido seja o primeiro passo para que filhos de alcoolistas alcancem uma vida criativa e com sentido.

CAMPO 4: DE VOLTA A MINHA VIDA! 
O presente campo de sentidos afetivo-emocionais aborda a experiência dos filhos de alcoolistas que conseguem superar as experiências traumáticas e reconstruir a própria vida a partir de uma rotina na previsibilidade, segurança e confiança necessárias à manutenção da saúde mental. O drama de Rosa Vermelha ilustra esse processo de individuação em que uma retomada da espontaneidade reprimida ocorre em função da oferta de um novo ambiente humano capaz de acolher o gesto espontâneo. Com o afastamento da dinâmica familiar, e consequentemente do padrão de invasão ambiental, Rosa passa a integrar o vivido como parte de suas experiências que agora se ampliam para além das reações defensivas abrindo espaço para expressões do self.

Observamos essa nova qualidade de vivência no relato de Rosa sobre o amor e orgulho que sente hoje pelo pai, apesar da violência que foi vivida no passado. Rosa reconhece que o pai lhe ensinou o valor da autonomia, que hoje sente-se capaz e independente para todo o tipo de tarefa, inclusive aquelas socialmente atribuídas aos homens, como consertar um problema no motor do carro, levantar e rebocar uma parede com argamassa.

Hoje, Rosa consegue conversar com o pai sobre o passado e até brincar com o assunto quando, por exemplo, se recorda das agressões vividas e brinca com o pai que hoje ele "apanharia feio" (sic) caso tentasse agredi-la. A despeito de um suposto sentimento de triunfo de Rosa acerca da perda da potência paterna, há que se enfatizar a capacidade elaborativa de Rosa ao integrar o sofrimento vivido por meio do brincar (Winnicott, 1971/1975a) e assim se reaproximar do pai para estabelecer um vínculo afetivo e saudável.

A retomada dos processos criativos foi observada nos demais participantes deste estudo que, assim como Rosa, conseguiram ressignificar os conflitos provocados pela intoxicação alcoólica paterna. Fundamentados em Winnicott (1971/1975b) compreendemos que a capacidade dos filhos recuperarem a própria história reflete a potência dos processos integrativos do self, que caminham no sentido da autorrealização do indivíduo. Nesse sentido, os filhos de alcoolistas buscam inconscientemente alcançar o viver criativo winnicottiano, no qual o self verdadeiro pode se manifestar no mundo, a partir da integração das vivências cuja dissociação visou a proteção defensiva do self.

É esse mesmo movimento integrativo de Rosa que lhe permitiu, durante a entrevista, revisitar o passado com os olhos do presente, isto é, na perspectiva daquele que aprendeu com a experiência e atingiu um novo patamar de maturidade emocional. Sem se confundir com o pai, Rosa encontrou uma forma de resgatar qualidades da figura paterna ao escolher a mesma profissão que ele exercia quando ela era uma criança. Além de encontrar mais um motivo para estar perto dele conversando sobre assuntos do trabalho, Rosa está comunicando inconscientemente que a escolha pela profissão de motorista remete ao seu desejo de conduzir a própria vida, para que ela seja real e significativa. 


\section{CONSIDERAÇÕES FINAIS}

A experiência de Rosa foi aqui tomada como exemplar, na medida em que comunica o sofrimento compartilhado por filhos de alcoolistas. Os campos de sentidos afetivo-emocionais revelam um ambiente instável e ameaçador que os filhos de dependentes de álcool se esforçam por compreender, construindo teorias explicativas e assumindo uma função mediadora e conciliadora diante dos conflitos familiares. Em ambas as situações, observamos que o indivíduo está se movimentando no sentido de preservar o sentido de continuidade de ser e integrar as experiências vividas em torno de um verdadeiro self. Rosa nos ajudou a compreender que para garantir a própria sobrevivência emocional, os filhos têm seu viver marcado por estratégias defensivas que inibem o gesto espontâneo e a criatividade cujo retorno para o indivíduo é o sentimento de estar vivo e que a vida vale a pena ser vivida (Winnicott, 1960/1990; 1971/1975b). Como porta-voz de outros familiares de alcoolistas, Rosa comunica o desejo de viver a própria vida, não a de seu pai, ousando ser espontânea e autêntica assim que encontra uma alternativa de acolhimento.

Salientamos que a maturidade emocional e a posterior elaboração do vivido favorecem a retomada dos processos criativos que porventura tenham sido interrompidos por invasões ambientais e que aguardavam uma oportunidade para ressurgirem. Contudo, nem todos os filhos de alcoolistas são resilientes nem capazes de ressignificar suas vivências, mas como considerar esta situação ultrapassaria os objetivos deste estudo, contentamo-nos em compartilhar e discutir a experiência de Rosa em sua potencialidade para comunicar tanto o sofrimento que o convívio com um pai alcoolista significa quanto para apontar caminhos de recuperação.

Esperamos que a produção desse conhecimento venha a subsidiar práticas profissionais de cuidado que focalizem as necessidades dos filhos do alcoolista, frequentemente negligenciadas nas intervenções profissionais que tendem a focalizar seus esforços no alcoolista. Assim como Rosa viveu o desamparo no seio familiar, inúmeros filhos de alcoolistas podem estar sofrendo com as marcas da violência doméstica e intrusão ambiental. Considerando o cenário brasileiro em que serviços públicos de saúde e assistência social estão inseridos no território do indivíduo, salientamos a importância de um cuidado profissional afinado às necessidades dessa população que pode usufruir do serviço para se reorganizar psicologicamente e conseguir auxílio e tratamento para si, para o progenitor alcoolista e para os demais familiares.

A despeito das pesquisas qualitativas não permitirem uma extensa generalização de seus achados, dado seu enfoque na singularidade das experiências vividas, salientamos que o estudo psicanalítico tem o mérito de oferecer uma leitura aprofundada da experiência emocional de um coletivo representado por Rosa, auxiliando o profissional a afinar sua escuta para o sofrimento dessa população. Como última reflexão, destacamos a importância da formação continuada dos 
profissionais da saúde mental especializados em álcool e drogas, de modo a integrar o cuidado aos familiares em sua prática. Se Rosa precisou de um ambiente suficientemente bom para ressignificar o seu passado, podemos supor o potencial dos profissionais/serviços ao sustentar emocionalmente os familiares do alcoolista que buscam uma condição ambiental para existir.

\section{REFERÊNCIAS}

Aiello-VaisBerg, T. M. J., Machado, M. C. L., Ayouch, T., Caron, R., Beaune, D. (2009). Les récits transférentiels comme présentation du vécu clinique: Une proposition méthodologique. In D. Beaune (Ed.), Psychanalyse, Philosophie, Art: Dialogues (pp. 39-52). Paris: L'Harmattan.

Albuquerque, F. M. P., Heimerdinger, V. S., \& Rodrigues, E. F. (2016). Implicações do uso de álcool no exercício das funções parentais na perspectiva do filho adolescente. Revista Contexto \& Saúde, 16(31), 149-164. doi:10.21527/2176-7114.2016.31.149-164.

Benjamin, W. (1996). O narrador: Considerações sobre a obra de Nicolai Leskov. In W. Benjamin, Magia e técnica, arte e política: Ensaios sobre literatura e história da cultura (pp. 197-221). São Paulo, SP: Brasiliense. (Trabalho original publicado em 1936).

Bleger, J. (1984). Psicologia da Conduta. Porto Alegre, RS: Artmed. (Trabalho original publicado em 1963).

Colossi, P. M., Marasca, A. R., \& Falcke, D. (2015). De geração em geração: A violência conjugal e as experiências na família de origem. Psico, 46(4), 493-502. doi:10.15448/19808623.2015.4.20979.

Feijó, M. R., Noto, A. R., Silva, E. A., Locatelli, D. P., Camargo, M. L., \& Gebara, C. F. P. (2016). Álcool e violência nas relações conjugais: Um estudo qualitativo com casais. Psicologia em Estudo, 21(4), 581-592. doi:10.4025/psicolestud.v21i4.31556.

Ferraboli, C. R., Guimarães, A. N., Kolhs, M., Galli, K. S. B., Guimarães, A. N., \& Schneider, J. F. (2015). Alcoolismo e dinâmica familiar: Sentimentos manifestos. Ciência, Cuidado e Saúde, 14(4), 1555-1563. doi:10.4025/cienccuidsaude.v14i4.27245.

Flick, U. (2013). Introdução à metodologia de pesquisa: Um guia para iniciantes. Porto Alegre, RS: Penso.

Fulgêncio, L. (2015). Apontamentos para uma análise da influência do existencialismo moderno na obra de Winnicott. Ciência e Cultura, 671), 36-39. doi: 10.21800/2317-66602015000100013.

Furtado, E. F., Laucht, M., \& Schmidt, M. (2002). Estudo longitudinal prospectivo sobre o risco de adoecimento psiquiátrico na infância e alcoolismo paterno. Revista Psiquiatria Clínica, 29(2), 71-80.

Granato, T. M. M., \& Aiello-Vais Berg, T. M. J. A. (2013). Narrativas Interativas sobre o cuidado materno e seus sentidos afetivo-emocionais. Psicologia Clínica, 25(1), 17-35.

Hagstöm, A. S., \& Forinder, U. (2019). 'If whistled in her ear she'd wake up': Children's narration about their experiences of growing up in alcoholic families. Journal of Family Studies. Advance online publication. doi:10.1080/13229400.2019.1699849.

Haverfiel, M. C., Theiss, J. A., Leustek, J. (2015). Characteristics of communication in families of alcoholics. Journal of Family Communication, 16(2), 111-127. doi:10.1080/15267431.2016.1146284.

Hermel, J. S., \& Drehmer, L. B. R. (2013). Repercusões da violência intrafamiliar: Um estudo com mulheres em acompanhamento psicológico. Psicologia Argumento, 31(74), 437-446. doi:10.7213/psico.argum.31.074.DS07

Herrmann, F. (2001). Andaimes do real: O método da psicanálise. São Paulo, SP: Casa do Psicólogo. (Trabalho original publicado em 1979).

Lopes, A. P. A. T., Marcon, S. S., \& Deceraso, M. N. (2015). Abuso de bebida alcoólica e sua relação no contexto familiar. Estudos de Psicologia, 20(1), 22-30. doi:10.5935/1678-4669.20150004

Lopes, R. F. F., Maia, L. H. C., \& Lopes, M. C. F. F. (2019). Tríade cognitiva e crenças centrais no Children Apperception Test (CAT) em filha de pai alcoolista. Perspectivas em Psicologia, 23(1), 03-28. doi:10.14393/ppv23n1a2019-50598

Mangueira, S. O., \& Lopes, M. V. O. (2014). Família disfuncional do contexto do alcoolismo: análise de conceito. Revista Brasileira de Enfermagem, 671), 149-154. doi:10.5935/00347167.20140020 
Ordem, T. (2018). Esta arte da Psicanálise: Sonhando sonhos não sonhados e gritos interrompidos. Porto Alegre, RS: Artmed.

Pereira, V. C. L. S., Pimentel, L. F., Espínola, L. L., Azevedo, E. B., \& Filha, M. O. F. (2015). Sofrimento psíquico em adolescentes que vivenciam alteração da dinâmica familiar em consequência do alcoolismo. Revista de Enfermagem da UERJ, 23(6), 838-844. doi:10.12957/reuerj.2015.21629

Politzer, G. (1998). Crítica dos fundamentos da psicologia: A psicologia e a psicanálise. Piracicaba, SP: Editora Unimep. (Trabalho original publicado em 1928).

Ricoeur, P. (1991) O si-mesmo como um outro. Campinas, SP: Papirus.

Santos, A. M., Silva, M. R. S., \& Silva, P. A. (2012). O cotidiano dos filhos que convivem com a mãe alcoolista. Ciência, Cuidado e Saúde, 11(4), 697-703. doi:10.4025/cienccuidsaude.v11i4.16897

Silva, A. I. M. (2016). Crianças filhas de pais alcoólicos: Prevenção de comportamentos de risco. In M. M. S. Rocha, N. Ramos, S. M. M. Santos, \& M. D. H. Costa (Eds.), Seguridade social, interculturalidades e desigualdade na contemporaneidade (pp.271-308). Fortaleza, CE: EDUFRN. Disponível em http://hdj.handle.net/10400.2/6374

Silva, M. E. L. (1993). Investigação e psicanálise. Campinas, SP: Papirus.

Silva, P. A., Silva, M. R. S., \& Vaz, M. R. C. (2013). Características pessoais de filhos de alcoolistas: Um estudo na perspectiva da resiliência. Avances en Enfermería, 31(2), 92-100.

Singh, A. (2017). Self-efficacy and well-being in adolescent children of alcoholic parents. Indian Journal of Health \& Wellbeing, 8(7), 619-621.

Souza, J., \& Carvalho, A. M. P. (2012). Filhos adultos de pais alcoolistas e seu relacionamento na família de origem. Saúde \& Transformação Social, 3(2), 43-51.

Stake, R. E. (2011). Pesquisa qualitativa: Estudando como as coisas funcionam. Porto Alegre, RS: Editora Penso.

Stefanini, J. R., Juan-Marínez, B., Silva, D. T. G., \& Farinha, M. G. (2019). Violência intrafamiliar e as repercussões para a saúde da mulher: Compreendendo a história de Antônia. Revista da NUFEN: Fenomenologia e Interdisciplinariedade, 11(1), 122-136. doi:10.26823/revistadoNUFEN.vol11.n01artigo49

Teixeira, E. P., Hoepers, N. J., Correa, S. M., Dagostin, V. S., \& Soratto, M. T. (2015). O enfrentamento da família diante do alcoolismo. Revista Saúde e Comunicação, 11(3), 1-14.

Tinnfält, A., Fröding, K., Larsson, M., \& Dalal, K. (2018). "I feel it my heart when my parents fight": Experiences of 7-9-year-old children of alcoolics. Child \& Adolescent Social Work, 5, 531540. doi: 10.1007/s10560-018-0544-6.

Winnicott, D. W. (1975a). Objetos transicionais e fenômenos transicionais. In D. W. Winnicott, $O$ Brincar \& a Realidade (pp. 10-47). Rio de Janeiro, RJ: Editora Imago. (Trabalho original publicado em 1971).

Winnicott, D. W. (1975b). A criatividade e suas origens. In D. W. Winnicott, O Brincar \& a Realidade (pp. 108-138). Rio de Janeiro, RJ: Editora Imago. (Trabalho original publicado em 1971).

Winnicott, D. W. (1971). Therapeutic consultations in child psychiatry. New York, NY: Basic Books.

Winnicott, D. W. (1990). Distorção do ego em termos de verdadeiro e falso self. In D. W. Winnicott, O Ambiente e os processos de maturação: Estudos sobre a teoria do desenvolvimento emocional (pp. 128-139). Porto Alegre, RS: Artmed. (Trabalho original publicado em 1960).

Winnicott, D. W. (1990). Provisão para a criança na saúde e na crise. In D. W. Winnicott, O ambiente e os processos de maturação: Estudos sobre a teoria do desenvolvimento emocional (pp. 6269). Porto Alegre, RS: Artmed. (Trabalho original publicado em 1962).

Winnicott, D. W. (1993). A construção da confiança. In D. W. Winnicott, Conversando com os pais (pp. 139-152). São Paulo, SP: Martins Fontes. (Trabalho original publicado em 1969).

Winnicott, D. W. (1994). O medo do colapso. In D. W. Winnicott, Explorações Psicanalíticas (pp. 7076). Porto Alegre, RS: Artmed. (Trabalho original publicado em 1963).

Winnicott, D. W. (2000). Preocupação materna primária. In D. W. Winnicott, Da pediatria à psicanálise, (pp.399-405). Rio de Janeiro: Imago (Trabalho original publicado em 1956).

Woodside, M. (1988). Children of alcoholics: Helping a vulnerable group. Public Health Reports, 103(6), 643-648.

Zanello, V., \& Martins, F. (2010). O reencontro da clínica com a metáfora. Psicologia em Estudo (Maringá), 15(1), 189-196. doi: 10.1590/S1413-73722010000100020 


\section{AGRADECIMENTOS}

Agradecimentos ao Conselho Nacional de Desenvolvimento Científico e Tecnológico (CNPq).

\section{CONFLTTOS DE INTERESSES}

Não há conflito de interesses.

\section{FINANCIAMENTO}

O presente trabalho foi realizado com apoio do CNPq, Conselho Nacional de Desenvolvimento Científico e Tecnológico - Brasil (Processo n 131290/2017-7).

\section{SOBRE OS AUTORES}

Antonio Richard Carias é psicólogo, mestre e doutorando em Psicologia pela Pontifícia Universidade Católica de Campinas. Bolsista de Doutorado do CNPq - Brasil. Trabalha na linha de pesquisa Intervenções Psicológicas e Processos de Desenvolvimento Humano, particularmente no tema de família e saúde mental.

E-mail: psicologo.antoniorichard@gmail.com

\section{(1) https://orcid.org/0000-0001-7222-874X}

Tânia Mara Marques Granato é psicóloga, mestre e doutora em Psicologia Clínica pelo Instituto de Psicologia da Universidade de São Paulo. Realizou estágio de pós-doutorado com bolsa FAPESP na Pontifícia Universidade Católica de Campinas. É docente e orientadora no Programa de PósGraduação em Psicologia da Pontifícia Universidade Católica de Campinas. Trabalha na linha de pesquisa Intervenções Psicológicas e Processos de Desenvolvimento Humano, particularmente no tema de família e relações pais-filhos.

E-mail: granatotania@gmail.com

(1) https://orcid.org/0000-0002-2912-0693 